\title{
Experiential education as a strategy to preserve Maqasid Al-Shariah by identifying and addressing stigmatic views held by pharmacy students of patients with substance use disorders.
}

\author{
Nor Hidayah Mohd Taufek ${ }^{1,2^{*}}$, Syafiqah Nadiah Halimi ${ }^{1}$, Norny Syafinaz Ab Rahman ${ }^{1,2}$, Che \\ Suraya Zin ${ }^{1,2}$, Che Anuar Che Mohamad ${ }^{3}$ and Christopher John Turner ${ }^{4}$
}

\section{ABSTRACT}

Introduction: Stigmatising people with a history of substance use disorders (PHSUDs) is discriminatory, causes harm by hindering access to health services and promotes relapse. It jeopardises the preservation of Maqasid Al-Shariah, particularly the protection of life and well-being. Experiential education (EE) is a potential strategy to overcome stigma through direct experience with PHSUDs. This study aimed to identify stigmatised views of PHSUD's held by pharmacy students and, in accord with Maqasid Al-Shariah, the effectiveness of EE in changing those views.

Materials and methods: Interviews were conducted with seven undergraduate pharmacy students who provided care to PHSUDs through an EE programme. A semi-structured interview guide was used to explore students' perceptions on stigma. Each interview was audio-taped, transcribed verbatim and translated into English. Data were manually sorted and coded using Microsoft Excel 2016 and subjected to thematic analysis.

Results: The following themes related to stigma were identified: 1) individuals are to blame 2) moral versus biological views of addiction 3) stereotypes of unpredictability and dangerousness 4) lack of didactic education/training for pharmacy students regarding PHSUDs and 5) lack of face-to-face experiential education with PHSUDs. Less stigma and greater empathy towards PHSUDs were reported post-intervention attributable to increased knowledge about substance abuse and face-toface interactions with PHSUDs.

Conclusion: Pharmacy students have pre-conceived stigmatic views regarding PHSUDs modifiable through experiential education. Contact by pharmacy students with stigmatised patients promotes health care without discrimination as advocated in the teaching of Islam. Future interventions to reduce stigma are required to preserve Maqasid Al-Shariah.

\section{ARTICLE HISTORY:}

Received: 17 July 2020

Accepted: 8 October 2020

Published: 8 January 2021

\section{KEYWORDS:}

Stigma, experiential education, substance use disorders, protection of life, Maqasid AlShariah.

\section{HOW TO CITE THIS ARTICLE:}

Mohd Taufek, N. H., Halimi, S. N., Ab Rahman, N. S., Zin, C. S., Che Mohamad, C. A. \& Turner, C. J. (2021). Experiential education as a strategy to preserve Maqasid AlShariah by identifying and addressing stigmatic views held by pharmacy students for patients with substance use disorders. Journal of Pharmacy, 1(1), 1-7.

\section{${ }^{*}$ Corresponding author:}

Email address: hidayahtaufek@iium.edu.my Tel:+609 571 6400, Fax: +609 5716775

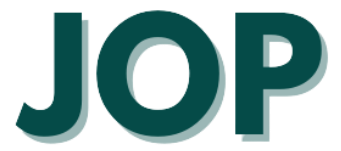

\section{Authors' Affiliations:}

\footnotetext{
${ }^{1}$ Department of Pharmacy Practice, Kulliyyah of Pharmacy, International Islamic University Malaysia, Jalan Sultan Ahmad Shah, 25200 Kuantan, Pahang.

${ }^{2}$ Substance Use Disorders Research Group, Kulliyyah of Pharmacy, International Islamic University Malaysia, Kuantan, Malaysia.

${ }^{3}$ Department of Basic Medical Sciences, Kulliyyah of Pharmacy, International Islamic University Malaysia, Jalan Sultan Ahmad Shah, 25200 Kuantan, Pahang. ${ }^{4}$ Retired but formerly with Skaggs School of Pharmacy and Pharmaceutical Sciences, University of Colorado Anschutz Medical Campus, Aurora, United States.
} 


\section{Introduction}

Stigma complex is defined as "the set of interrelated, heterogeneous system structures, from the individual to the society, and processes, from the molecular to the geographic and historical, that constructs, labels, and translates difference into marks" (Pescosolido \& Martin, 2015). Negative marks associated with substance use disorders (SUDs) include health, social and behavioural dispositions at odds with societal expectations (e.g. unemployment and crime) that result in social rejection (Committee on the Science of Changing Behavioral Health Social Norms et al., 2016). Manifestations of stigma affect health outcomes negatively. They hinder health-seeking behaviour, limit allocation of resources for treatment/intervention and dissuade health care professionals from providing services (Yang et al., 2017). Accordingly, it is important to identify and address negative views held by current and future healthcare professionals towards people with a history of substance use disorders (PHSUDs). That is especially important for Muslim healthcare professionals because holding stigmatised views is inconsistent with the Islamic principles of Maqasid AlShariah (Raysuni, 2005).

Maqasid Al-Shariah refers to the higher objectives of the Islamic law that emphasise the protection/preservation of basic human rights including five fundamental elements: faith/religion, life, lineage/offspring, intellect and wealth/property (Raysuni, 2005). Preservation of the elements can be achieved through efforts related to establishing and strengthening them and by removing potential threats such as poor health (Ibn Ashur, 2006). Stigma towards PHSUDs has been associated with poor health outcomes (Crapanzano et al., 2018).

Didactic and experiential education are effective strategies in changing stigmatised attitudes towards SUDs (Committee on the Science of Changing Behavioral Health Social Norms et al., 2016). Experiential education in pharmacy education involves direct interaction between students and patients in clinical and public healthcare settings and is an important strategy to improve the competency of future pharmacists (Legal, 2019). However, research is lacking in addressing stigma associated with SUDs among pharmacy students. This study sought 1) to identify stigmatised views held by pharmacy students towards PHSUDs and the influence of experiential education on those views and 2) to discuss the value to students of providing healthcare for PHSUDs with respect to the Islamic principles of Maqasid Al-Shariah.

\section{Methodology}

This study received ethical approval from the
International Islamic University Malaysia (IIUM) Research Ethics Committee (ID No. IREC 2019-026). Eligibility criteria for participants were students who completed the IIUM Drug Abuse course PHM 3282, volunteered to be trained in providing face-to-face health screening services to PHSUDs and consented to be interviewed. PHSUDs were people who completed drug rehabilitation treatment and were monitored by the Malaysian government's National Anti-Drug Agency (NADA) in Kuantan, Malaysia. The activities undertaken by the students during the programme were screening of blood pressure, glucose, lipid and carbon monoxide levels.

A qualitative study that involved semi-structured face-to-face interviews was conducted with all (7) students who met the eligibility requirements, at the Faculty of Pharmacy, IIUM. It was conducted from January until May 2019 at mutually convenient times arranged by the interviewer and each student. Students were contacted by the researchers who explained the purpose and nature of the study. One-on-one interviews were conducted in the Malay language by one interviewer using a general interview guide designed by the researchers to allow students to comment on their didactic knowledge, perceptions, experience, patient interactions and reflections pertinent to the study. Questions addressing barriers, problems, challenges during the experiential learning as well as positive and negative feelings specific to PHSUDs were emphasised to obtain detailed elaboration on stigma, importance of health services to PHSUDs from educational, health and Islamic perspectives. When deemed necessary, questions were repeated and/or rephrased to confirm the students' understanding of the questions asked and to confirm the interviewer's understanding of the students' answers. The interviews were audiotaped, transcribed verbatim and translated into English. The names of participants were kept anonymous for privacy protection.

A thematic analysis of the transcripts was undertaken to identify, analyse, and report recurring themes relevant to the study (Braun \& Clarke, 2006). Data (relevant phrases, sentences, etc.) were copied from each transcript to a Microsoft Excel spreadsheet and manually sorted to facilitate the identification and coding of recurring themes. That process was conducted independently by two researchers and differences in the identification and coding of themes were resolved through discussion. There is no established ideal sample size when using thematic analysis. Most qualitative studies use the concept of saturation, the point at which no new information or themes are observed in the data (Guest, Bunce \& Johnson, 2006; Willig, 2013; Fugard \& Potss, 2015). 
Table 1: Views held by pharmacy students towards SUDs and the influence of experiential education on those views.

Themes

Individuals are to blame

\section{Quotes}

"We tend to blame the drug addicts that they don't want to try to go back to the right path...after they go for rehab, they relapse" (P6)

"I had this stigma on why we should spend a large amount of money in helping them because it is their own problem. Why did they involve in drug abuse and difficult to be cured?" (P2)

"mostly come from low education status... rural area, they involved with drugs influence by their friends" (P4)

"drug abusers as those who are from disorganised family institution" (P5)

"I felt uncomfortable because people who involved with drugs may have HIV...they were also not really friendly" (P7)

\section{Moral versus biological views of addiction}

"I learned how drugs affect the health of drug users, addiction can affect their mental health, physiological, quality of life and attitude...I can see that it is a disease, not only because of themselves" (P2)

"I thought that people who took drugs just wanted to have fun, they didn't want to quit drugs...we know that withdrawal syndromes involve physiology of their body...same with other chronic diseases...so it is partly not their will" (P7)

\section{Stereotypes of unpredictability and dangerousness}

"At first I was quite scared because may be some of them could become aggressive...cheating... we don't know if they have withdrawal symptoms" (P1)

"From afar, I saw that they were quite rough in terms of personality, so I was a bit scared to have a chat with them" (P4)

"Concern about their behaviour...those who have difficulty to cooperate" (P5)

"How do we communicate with these people...because drug (addiction) is a sensitive issue" (P6)

\section{Lack of} education/training among students
"We only learned theory previously, we know better now from experience" (P1)

"Experiential learning is important. When we understand about how drugs affect them in reality... it can change our thought on them" (P2).

"Those who did not take the course (IIUM Drug Abuse course PHM 3282), they lack preparation...we need to have more hands-on experiences so that students are confident to do it...no more fear of doing such activities. We can also learn from psychological aspect...or behavioural knowledge... about the best method to approach them" (P7) 
Lack of contact with PHSUDs

"There should be more exposure to ex-drug addicts in terms of teaching and learning" (P3)

"it was a totally new experience, I got to know their behaviour...some of my friends did not want to involve when they knew that this program involved ex-drug users" (P4)

"He told us about how many cigarettes he smoked before...this population is a bit unique...we need to know their behaviour...because different people require different methods" (P5)

"This programme was an opportunity for me to meet and observe them...positive experience... I could interact with them and they shared their stories how they got involved with drugs" (P6)
Reduced stigma and increased empathy following direct contact
"Before the programme, I felt a bit scared and nervous, and some negative thought. After that I felt like they were similar to other patients...they told stories...we got some insights how hard it was for them to quit drugs... when they went to the clinic to seek treatment, the public had sceptical opinion towards them...sometimes even the hospital staff were being sarcastic and teasing them...they felt inferior, they did not want to go anymore" (P1)

"It changed my stigma about them...I wanted to help them" (P2)

"They said that they did not usually do health screening... so when we do it, they seemed to appreciate the services...we should get to know their community better" (P3)

"In Islam, smoking cigarette is forbidden...I observed the bad things that happened to the patients from smoking based on their stories...so it strengthens the fact that smoking should be avoided completely...if we do not care about them properly they could relapse" (P5)

"Improved my perspective on drug addict, not all of them wanted to involve with drugs...a patient told us that he took morphine to relieve the pain due to an illness...then he got addicted" (P6)

"this programme gave us more understanding and empathy towards this population" (P7) 
Saturation was deemed to have occurred in this study after five students were interviewed. Data triangulation process related to stigma and substance use disorders, as well as Islamic concept of both components in relation to Maqasid al-Shariah were compared with the literature and audit trail conducted during the interview for differences and similarities.

\section{Results}

The seven participants (age 23-25 years) were female, Malay, single, final year undergraduate pharmacy students. The total duration of the interviews was 204 minutes and ranged from 21 minutes to 37 minutes and average length of 29 minutes. The variation in length was due to different student responses to questions and the requirement to ask for clarification regarding some responses. Six themes are identified and are described in Table 1 using italicised quotes from the transcripts. The participants were identified using the participant number (e.g. P6).

\section{Individuals are to blame}

Stigma was manifested by blaming individuals for 1) becoming drug addicts, 2) relapsing after treatment, 3) succumbing to peer pressure, 4) unwillingness to quit drugs or to be treated, 5) the large amount of resources required to treat addiction and its co-morbidities including human immunodeficiency virus (HIV) infections and 6) their backgrounds - they described PHSUDs as individuals with low education and coming from a dysfunctional family in rural areas. They implied that PHSUDs were unfriendly.

\section{Moral versus biological views of addiction}

Students expressed both moral and biological views and could link both components. The moral views were described in terms of addiction habit, reluctance to seek professional help, negative attitudes and desire to have short-term pleasure. The biological view was implied by knowledge regarding SUDs in terms of biological changes in the body and viewing drug addiction as a chronic disease associated with withdrawal syndromes and relapse. The biological view of addiction was linked with mental health, quality of life and attitude.

\section{Stereotypes of unpredictability and dangerousness}

Students reported that they had negative thoughts on the behaviour and personality of PHSUDs. They described them as aggressive, cheating, uncooperative, anxious and rough as well as the possibility that they might exhibit withdrawal symptoms. They were concerned as to the best way to communicate with PHSUDs given the sensitivity of some issues.

\section{Lack of education/training among students}

The students reported that their education and training in SUDs was lacking and that theory and experiential education needs to be balanced. They reported on the need to focus on the best ways to gain the trust of PHSUDs such that they are willing to engage with healthcare practitioners. They expressed concern that their peers who did not participate in the course and programme will not have the knowledge and skills to care for PHSUDs.

\section{Lack of contact with PHSUDs}

Students reported that the programme was their first encounter PHSUD patients. They described it as a positive experience where interaction with PHSUDs improved their understanding of SUDs. They perceived that PHSUDs possessed unique behaviours compared with the general public and were concerned that some of their peers refused to participate in the programme because the patients were PHSUDs. The face-to-face interactions enabled the students to gain patients' trust and to discuss and address each patient's individual needs.

\section{Reduced stigma and increased empathy following direct contact}

The students reported that their experience improved their empathy towards PHSUDs and, with a changed perception, now saw PHSUD patients in the same way they saw other patients. The exchange of information and stories during the programme provided the students with insights into the reality of their patients' struggles to quit drugs and the circumstances surrounding the development of their addiction. They expressed empathy in terms of the challenges to accessing healthcare due to stigma. They were motivated to help this population with their overall health care and to prevent relapse. Islamic values were reflected regarding smoking tobacco in that smoking may lead to other forms of addiction.

\section{Discussion}

The study provides evidence that pharmacy students hold stigmatised views of PHSUDs likely driven by preconceived ideas regarding SUDs common in the general population. In addition, the results provide evidence that experiential education involving face-to-face contact with PHSUDs can improve pharmacy students' views of PHSUDs and promote their interest in experiential education and didactic education regarding SUDs. The finding that pharmacy students hold stigmatised views of PHSUDs is important because stigma limits PHSUDs access to health care (Merril \& Monti, 2015). Avoidance of negative labels has been reported as an important factor in encouraging individuals with SUDs to seek help from healthcare providers (Ciftci, Jones \& Corrigan, 2012) and, accordingly, it is important to identify and address negative views held by healthcare professionals regarding SUDs. It has been reported that lack of education, training and support for health professionals working with stigmatised patients creates barriers, reduces engagement and 
diminishes empathy (Van Boekel et al., 2013).

The finding that face-to-face interactions reduced stigma and generated empathy towards PHSUDS is important because it provides evidence that experiential education can change Malaysian students' pre-conceived stigmatised views of PHSUDs. The finding that students felt their experience should become a core component of the curriculum (e.g. involve all pharmacy students) and that more didactic education regarding SUDs should be included in the curriculum is important in demonstrating that experiential education can motivate and improve student learning. Early and continuous experiential education has been identified in an evidence-based literature review as an important component of the pharmacy curriculum (Speedie et al., 2012). Relevant to this study, though not reported directly in the published manuscript, even first-year pharmacy students have had interactions with PHSUDs in community pharmacy-based methadone clinics (Winn \& Turner, 2016).

Malaysia is a Muslim country and healthcare practitioners need to be culturally competent with respect to the Maqasid Al-Shariah principles of basic human rights including life, health and well-being (Attum et al., 2020). Islamic teaching encourages understanding and empathy and discourages assumption and speculation. In that light, holding stigmatised views can be considered as sinful as demonstrated in the following Quranic verses:

"O you who have believed, let not a people ridicule [another] people; perhaps they may be better than them; nor let women ridicule [other] women; perhaps they may be better than them. And do not insult one another and do not call each other by [offensive] nicknames. Wretched is the name of disobedience after [one's] faith. And whoever does not repent - then it is those who are the wrongdoers" (49:11).

"O you who have believed, avoid much [negative] assumption. Indeed, some assumption is sin..." (49:12).

These verses establish one important rule which is to avoid negative suspicion as this act is regarded as sinful. This would leave the heart to be clean together with more positive thoughts towards others (Qutb, 2002). The verses also indicate that it is forbidden for one group to deride other groups as we do not know for certain which groups enjoy a better status in the eyes of God. PHSUDs may possess values known only to God despite being socially disadvantaged. With proper care and treatment, those values could be identified and nurtured as part of the recovery process. The verses also imply the right of a person not to be treated disrespectfully which occurs commonly in stigmatised populations. Islam teaches that despite their history or previous sins, people should not call others by labels that inflict pain. Islamic teaching goes even further in establishing a noble society with high standard of justice and fairness as reflected in the following Quranic verse:
"And do not let your dislike of a people lead you to be unjust $(5: 8)$. In our context, this verse teaches us as healthcare professionals to maintain our standard of care to all patients regardless of their appearance or background.

Islamic teachings are against harmful practices such as substance abuse that intoxicates the mind leading to loss of self-control and prevents remembrance of Allah. However, those teachings acknowledge human limitations and require that individuals should be given opportunities to repent and correct their mistakes. People should be helped to return to normal life instead of being stigmatised and discriminated against in ways that can limit access to health care and lead to relapse. Healthcare professionals including pharmacists are responsible for delivering fair and equal services to all patients. They should care for PHSUDs with compassion and empathy to develop mutual trust and promote compliance as required by Maqasid Al-Shariah.

Our study suggests that higher education models should explore the potential strategies of using experiential educational intervention to eliminate stigma among current and future health professionals. We propose the Islamic guideline of good manners e.g. avoid negative assumptions, being judgmental and degrading others, not to allow hatred to cause unequal services and injustice. These components need to be incorporated into the pharmacy curriculum. Failure to overcome stigma will eventually compromise the accessibility to basic healthcare services in marginalised groups of patients resulting in poor health outcomes.

The limitation of this study included a lack of variability in the student participants due to the small sample size (other themes or sub-themes may have emerged with a larger sample size). The findings of this study cannot be generalised to other population with different characteristics. Future research should include studies with larger sample sizes and with study subjects more characteristics of the general population.

\section{Conclusion}

Pharmacy students had pre-conceived stigmatic views toward patients with a history of substance use disorders. Experiential educational was a potential strategy in promoting empathy for stigmatised patients. Experiential education upholds the principle of Maqasid Al-Shariah that achievement of optimal health promotes the preservation of life.

\section{Acknowledgements}

The authors wish to thank the Drug Rehabilitation Committee of National Anti-Drug Agency Kuantan district for sponsoring the health programme for PHSUDs and the pharmacists at the Faculty of Pharmacy IIUM (Syed Mohd Syahmi Syd Mohmad Faudzi, Wan Zuhaira Amirah Wan Amran) who provided assistance and training for students and during programme. 


\section{References}

Attum, B., Hafiz, S., Malik, A., \& Shamoon, Z. (2020). Cultural Competence in the Care of Muslim Patients and Their Families. [Updated 2020 Jul 8]. In: StatPearls [Internet]. Treasure Island (FL): StatPearls Publishing; 2020 Jan-. Available from: https:/www.ncbi.nlm.nih.gov/books/NBK499933/

Braun, V., \& Clarke, V. (2006). Using thematic analysis in psychology. Qualitative Research in Psychology, 3(2):77-101.

Ciftci, A., Jones, N., \& Corrigan, P. (2012). Mental health stigma in the muslim community. Journal of Muslim Mental Health, 7(1): 17-32.

doi:https://doi.org/10.3998/jmmh.10381607.0007.102.

Committee on the Science of Changing Behavioral Health Social Norms, Board on Behavioral, Cognitive, and Sensory Sciences, Division of Behavioral and Social Sciences and Education, \& National Academies of Sciences, Engineering, and Medicine. (2016). Ending Discrimination Against People with Mental and Substance Use Disorders: The Evidence for Stigma Change. Washington (DC): National Academies Press (US). doi: 10.17226/23442.

Crapanzano, K. A., Hammarlund, R., Ahmad, B., Hunsinger, N., \& Kullar, R. (2018). The association between perceived stigma and substance use disorder treatment outcomes: a review. Substance Abuse and Rehabilitation, 10: 1-12. doi:10.2147/SAR.S183252.

Fugard, A. J. B., \& Potts, H. W. W. (2015). Supporting thinking on sample sizes for thematic analyses: A quantitative tool. International Journal of Social Research Methodology, 18(6), 669-684. doi: https://doi.org/10.1080/13645579.2015.1005453.

Guest, G., Bunce, A., \& Johnson, L. (2006). How many interviews are enough? An experiment with data saturation and variability. Field Methods. 18(1):59-82. 7. doi: $10.1177 / 1525822 \mathrm{X} 05279903$

Ibn Ashur, M. T. (2006). Treatise on Maqasid al-Shari'ah. Translated by Mohamed El-Tahir El-Mesawi. London: International Institute of Islamic Thought.

Legal, M. (2019). Advanced Strategies in Pharmacy Experiential Education. The Canadian Journal of Hospital Pharmacy, 72(3): 239-244.

Merrill, J.E., \& Monti, P.M. (2015). Influencers of the stigma complex toward substance use and substance use disorders. USA: Center for Alcohol and Addiction Studies, Brown University.

Pescosolido, B. A., \& Martin, J. K. (2015). The Stigma Complex. Annual Review of Sociology, 41: 87-116. doi:10.1146/annurev-soc-071312-145702
Qutb, S., Salahi, M. A., \& Shamis, A. A. (2002). In the Shade of the Quran. United Kingdom: Islamic Foundation .

Raysūnī, Ah-mad. (2005). Imam al-Shatibi's theory of the higher objectives and intents of Islamic law. London; Washington: International Institute of Islamic Thought.

Speedie, M. K., Baldwin, J. N., Carter, R. A., Raehl, C. L., Yanchick, V. A., \& Maine, L. L. (2012). Cultivating 'habits of mind' in the scholarly pharmacy clinician: report of the 2011-12 Argus Commission. American Journal of Pharmaceutical Education, 76(6), S3. https://doi.org/10.5688/ajpe766S3

van Boekel, L. C., Brouwers, E. P., van Weeghel, J., \& Garretsen, H. F. (2013). Stigma among health professionals towards patients with substance use disorders and its consequences for healthcare delivery: systematic review. Drug and alcohol dependence, 131(1-2), 23-35. https://doi.org/10.1016/j.drugalcdep.2013.02.018.

Willig, C. (2013). Introducing Qualitative Research in Psychology. 3rd ed. New York, NY: McGraw-Hill Education.

Winn, P., \& Turner, C. J. (2016). Description and Evaluation of an MPharm Practice-based Experience Pilot Program. American Journal of Pharmaceutical Education, 80(9), 151. https://doi.org/10.5688/ajpe809151

Yang, L. H., Wong, L. Y., Grivel, M. M., \& Hasin, D. S. (2017). Stigma and substance use disorders: An international phenomenon. Current Opinion in Psychiatry, 30(5), 378-388. https://doi.org/10.1097/YCO.0000000000000351 